\title{
PATRYK WITCZAK
}

(iD) https://orcid.org/0000-0002-5776-6176

Uniwersytet Kazimierza Wielkiego

Wydział Humanistyczny

Instytut Neofilologii i Lingwistyki Stosowanej

85-001 Bydgoszcz

ul. Grabowa 2

witczakptrk@wp.pl

\section{ПОЭЗИЯ ГАЛИНЫ КУЗНЕЦОВОЙ В КОНТЕКСТЕ ТВОРЧЕСТВА ИВАНА БУНИНА (ТЕМАТИЧЕСКИЙ АСПЕКТ)}

\author{
THE POETRY OF GALINA KUZNETSOVA \\ IN THE CONTEXT OF IVAN BUNIN'S WRITING \\ (THE THEMATIC ASPECT)
}

Галина Кузнецова - русская писательница, поэтесса, мемуаристка. Ее самым большим литературным достижением является Грасский дневник, в котором описывает жизнь с Иваном Буниным, который оказал сильное влияние на формирование художественной личности эмигрантки. В статье анализируются мотивы поэзии Кузнецовой (смерть, родина, любовь) в контексте лирики Бунина.

Ключевые слова: Галина Кузнецова, Иван Бунин, литература русского зарубежья, поэзия русской эмиграции.

Galina Kuznetsova was a Russian writer, poet and memorialist who belonged to the younger generation of the Russian Emigration (the first wave). Her most famous work is the so-called "Grasse Diary". Kuznetsova's place in the literature of the Russian emigration was determined by her liaison with Ivan Bunin. The present paper brings an analysis of certain motifs in Kuznetsova's poetry (homeland, death, love) precisely in the context of Bunin's poetry.

Keywords: Galina Kuznetsova, Ivan Bunin, Russian literature in exile, poetry of the émigrés.

Имя Галины Кузнецовой известно читателям и исследователям литературы русского зарубежья прежде всего не благодаря ее творческим достижениям, а обстоятельствам личной жизни. Напомним, что начинающая писательница привлекла внимание Ивана Бунина, вследствие чего стала 
его ученицей ${ }^{1}$. Долгие годы межвоенного периода Кузнецова провела на юге Франции в городе Грасс в одной вилле с Нобелевским лауреатом и его женой Верой Николаевной Муромцевой. Совместную жизнь в странном треугольнике молодая эмигрантка описала в Грасском дневнике. Судьба Кузнецовой отнюдь не оригинальна: эмигрантка повторяет схему литературного пути, характерную для многих других женщин-авторов. Стоит в этой связи напомнить творческие поиски Ирины Одоевцевой, Нины Берберовой и затем Кузнецовой. Однако, одновременно стоит согласиться с Ольгой Демидовой, которая справедливо отмечает, что «механизмы, на которые опиралась каждая из них, выстраивая свой писательский (авто)образ, были различны, как различна была их человеческая и творческая судьба ${ }^{2}$. Внешние сходства в судьбах эмигранток не лишали оригинальности их творческих поисков.

Кузнецовой было особенно сложно достичь творческой самостоятельности. В сознании многих современников она в своем творчестве оценивалась не как серьезная и талантливая писательница, а как «грасская Лаура», «последняя любовь» Бунина, его «удочеренная любовь» или «последний приз» ${ }^{3}$. Как утверждал в своих мемуарах Василий Яновский, Владислав Ходасевич определял Кузнецову частью «крепостного театра» лауреата Нобелевской премии ${ }^{4}$. Этот факт тяготил писательницу, о чем она неоднократно заявляла в своем дневнике 5

По мнению М. Михайловой, возрастное несовпадение, на которое указывает сама Кузнецова, было одной из главных причин творческого и личного расхождения молодой эмигрантки и Бунина ${ }^{6}$. Автор Жизни Арсеньева в эмигрантской среде считался человеком сложным, даже деспотом, он подавлял окружающих его людей, если у них не хватало сильного характера. Все это привело к тому, что Кузнецова решила покинуть Бунина и связаться с Маргаритой Степун. Однако, как оказалось, ей не удалось вполне освободиться от влияний окружающей ее среды, так как после того, как

${ }^{1}$ А. Соколов, Судьбы русской титературной эмиграции 1920-х годов, Москва: Издательство Московского университета 1991, с. 142.

${ }^{2}$ О. Демидова, Писательницы русской эмиграции: дважды Другие, [в:] Rossica Lubliniensia V: Kobieta i/jako Inny. Mit i figury kobiecości w literaturze i kulturze rosyjskiej XXXXI wieku (w kontekście europejskim), ред. M. Cymborska-Leboda, A. Gozdek, Lublin: Wydawnictwo UMCS 2008, c. 316.

${ }^{3}$ Там же, с. 319.

${ }^{4}$ В. Яновский, Поля Елисейские, Москва: Астрель 2011, с. 218.

${ }^{5}$ «Нельзя всю жизнь чувствовать себя младшим, нельзя быть среди людей, у которых другой опыт, другие потребности в силу возраста. Иначе это создает психологию преждевременного утомления и вместе с тем лишает характера, самостоятельности, всего того, что делает писателя». Г. Кузнецова, Грасский дневник, Москва: Астрель 2008, с. 157.

${ }^{6}$ М. Михайлова, Творческие взаимоотночения Ивана Бунина и Галины Кузнецовой как конфликт молодости и старости, „Slavica Wratislaviencisia” 2016, т. CLXII, с. 129-137. 
она уехала из Грасса со своей возлюбленной, она практически прекратила работать творчески. Можно подозревать, что подчиненность являлась одной из доминант внутреннего мира Кузнецовой. Об этом свидетельствуют письма Берберовой супругам Зайцевым

Таким образом, жизнь с Буниным с одной стороны, подавляла Кузнецову, с другой - мотивировала и стимулировала к творчеству. В межвоенные годы она издала две книги прозы (сборник рассказов Утро (1930) ${ }^{8}$, автобиографический роман Пролог (1933) и сборник стихотворений Оливковыцй cad $(1937)^{9}$, о котором будет речь в настоящем исследовании. После войны вышел только упоминаемый Грасский дневник $(1967)^{10}$, который был написан также в 30-ые годы XX века. Надо подчеркнуть, что поэзия Кузнецовой до сих пор не анализировалась, поэтому в статье сделана попытка охарактеризовать основные мотивы сборника Оливковый сад, которые преобладали и в поэзии Бунина эмиграционного периода.

Помимо того, что личность Бунина воспринималась в литературной среде «белой» эмиграции неоднозначно, никто не сомневался в его огромном таланте. Он внес неоценимый вклад в развитие отечественной литературы, той, которая развивалась и в метрополии, и за ее пределами. Некоторые ученые выделяют даже т. наз. «школу» Бунина ${ }^{11}$, однако, надо уточнить, что этот термин имеет более условный характер, так как непосредственное влияние автора Деревни на молодых писателей было ограниченным. К «школе» Бунина, как правило, причисляют Леонида Зурова, Николая Рощина и Кузнецову. Все они в межвоенные годы жили на бунинской вилле в Грассе. Говоря о «школе» Бунина, мы имеем в виду прежде всего прозаические художественные переклички. Рассказам и романам учеников Бунина свойствен лиризм, бессюжетность и импрессионистическая поэтика ${ }^{12}$. Тем

${ }^{7}$ «Что до Галины (кот. звонила мне сегодня), то тут патология совершенная. Марго живет «во всю», купила автомобиль, много выходит, знакомые. Гала избрала линию наименьшего сопротивления, забита до того, что покинуть не смеет. Не смеет опоздать домой, встретиться с кем-нибудь, уйти куда-нибудь из дому. Ее заикание очень ей мешает. [...] Так она и сидит, всегда жалуется, что много работы, что устает, никогда не улыбается, никогда! [...] Однако, видимо, «как-то» счастлива, цепляясь за любовь, боясь одиночества». Цит. за: О. Демидова, Писательницы русской эмиграции..., с. 322.

${ }^{8}$ Больше о цикле Утро см.: P. Witczak, Tworzenie w cieniu mistrza. Kilka uwag o prozie Galiny Kuzniecowej, „Heteroglossia. Studia kulturoznawczo-filologiczne” 2015, no. 5, c. 55-66.

${ }^{9}$ Г. Кузнецова, Оливковый сад, Париж: Современные Записки 1937. Все цитаты в этой статье происходят из этого издания, мы их приводим согласно современной орфографии.

${ }^{10}$ Больше о Грасском дневнике см.: J. Brzykcy, Dziennik z Grasse Galiny Kuzniecowej - autoportret pisarki, „Przegląd Rusycystyczny” 2016, r. 38, z. 1, c. 27-43.

${ }^{11}$ А. Соколов, Судьбы русской титературной эмиграции..., с. 142-145; Г. Струве, Русская титература в изгнании, Париж-Москва: Русский Путь 1996, с. 204-205.

${ }^{12}$ P. Witczak, Odchodzaca Rosja w powieści „Dawna podróż” Leonida Zurowa, „Acta Neophilologica" 2017, т. 19, no. 1, c. 227-236. 
не менее, на наш взгляд, о влиянии Бунина можно говорить и в случае поэзии Кузнецовой. Это влияние обнаруживается на уровне тематики и в присутствии «духа» поэзии великого мастера слова русской эмиграции. Стоит отметить, что близкий друг Кузнецовой - Михаил Цетлин - в рецензии на ее поэтический сборник писал:

Прежде всего хочется отметить их (стихотворений) неподражаемость. Совсем нет в них - почти неизбежного в женской поэзии - влияния Ахматовой. Те поэты, у которых она училась, научили ее естественно и правдиво передавать ее собственные переживания, ее душу ${ }^{13}$.

Хотя Цетлин пишет о зрелости Кузнецовой, он вспоминает также о ее учителях. Не приводит напрямую фамилии Бунина, однако можно подозревать, что он имел в виду именно автора Окаянных дней. Эмиграционный критик и редактор хорошо знал, что сама Кузнецова сомневалась в своей художественной самостоятельности.

Бунин всегда подчеркивал, что чувствует себя поэтом, однако поэзия в эмиграционном периоде его творчества занимала специфическое место. На чужбине писатель, хотя и не прекратил полностью сочинять стихотворений, обратился прежде всего к прозе. Сам автор с пренебрежением относился к делению литературных произведений на лирику и прозу и этот взгляд нашел свое отражение в его художественном стиле. Если для прозы Бунина характерен лиризм, то для его поэзии - прозаизация. Иоланта Бжикцы, анализируя эмиграционную поэзию Бунина, выделила несколько, доминирующих в ней, тематических групп: ход времени, который связан со сферой sacrum и любовью (eros), тайна смерти и отчизна ${ }^{14}$. Все эти мотивы присутствуют также и в лирических произведениях Кузнецовой, которая сочиняет их по-своему и одновременно обращается к поэтике Бунина.

Стихотворения Кузнецовой отдельной книгой были выпущены издательством «Современных записок» в 1937 г., но содержат лирические тексты, написанные в 1923-1929 гг. ${ }^{15}$ Только открывающее цикл стихотворение

${ }^{13}$ М. Цетлин, Галина Кузнецова. Оливковый Сад. Изд. «Совр. Записки». Париж. 1937, «Современные Записки» 1928, кн. LXV, с. 430.

${ }^{14}$ J. Brzykcy, Poezja emigracyjna Iwana Bunina (1920-1953), Toruń: Wydawnictwo UMK 2009, c. 7-16.

${ }^{15}$ Кузнецова познакомилась с Буниным в Париже в 1924 г., т.е. большинство своих стихотворений она написала уже под его сознательным или подсознательным влиянием. Подробнее о первой встрече Кузнецовой и Бунина см.: М. Духанина, «Монастырь Муз». К истории творческих и личных взаимоотночений Г. Н. Кузнецовой, И. А Бунина, Л. Ф. Зурова, В. Н. Муромиевой Буниной, М. А. Степун, [электронный ресурс] http://www.vestnik.com/ issues/2002/0612/win/dukhanina.htm [25.07.2018]. 
O, этот сад! было сочинено в 1937 г. Цитируемый выше Цетлин следующим способом объясняет неоднозначное на первый взгляд заглавие сборника: «Галина Кузнецова удачно назвала свой первый сборник стихов. Матово серебристые листья оливковых деревьев хорошо передают основной тон книги, слабое сияние, излучающееся от этих стихов» ${ }^{16}$.

Не только заглавие, но и первое стихотворение цикла передает его ностальгический настрой. Символика сада очень богата. Прежде всего в разных культурах мира, в том числе и христианской, сад ассоциируется с идеальным локусом и потерянным раем ${ }^{17}$. Такое толкование сада совпадает с переживаниями многих эмигрантов, которые, тоскуя по родине, сравнивали ее с божественным вертоградом и сильно идеализировали. Кроме того, надо подчеркнуть, что и оливковое дерево, вынесенное в заглавие сборника, к образу которого Кузнецова неоднократно возвращается в других стихотворениях, обладает разнообразной семантикой - это символ мира (Древо жизни), победы, очищения, долголетия и плодородия ${ }^{18}$. Стоит отметить, что поэтесса пользуется этими топосами нешаблонно, сопоставляя их положительную символику с мотивами печали, течения жизни и смерти. Сад выступает в роли не Элизиума, даюеег приют и счастье, а немого свидетеля тоски и грусти эмигрантов, который не в состоянии утешить страдающих («Сад принял слез младенческий поток»). Единственной возможностью найти внутренний покой является переход к потустороннему миру, земля дает утешение после смерти («Что гаснущим глазам казалась грудь земли/Единственным приютом и приветом...»). Таким образом, в строках предваряющего сборник стихотворения Кузнецова акцентировала проблемы, доминирующие в ее целом поэтическом наследии.

Книга Оливковый сад состоит из 61 стихотворения и подразделяется на две части, которые отличаются друг от друга затрагиваемой в них проблематикой или, точнее, частотой выступления определенной тематики, но надо подчеркнуть, что мотив ностальгии присутствует в целом цикле. В первой части преобладают стихи, посвященные родине и тоске по ней (Город, с. 11; Русь, с. 15; Такое небо бывает над снегом, с. 16; И я жила, за днем встречая день, с. 17; Мы в этот день любили всех людей, с. 27; Покидаю наш край счастливый, с. 31; Спокойная и грустная отрада, с. 35; Цветок иловый с пряным ароматом, с. 53). Лирическое «я» в глубинах

\footnotetext{
${ }^{16}$ М. Цетлин, Галина Кузнеизова..., с. 430.

${ }^{17}$ Энциклопедия символов, знаков, эмблем, сост. В. Андреева, В. Куклев, А. Ровнер, Е. Егазаров, Москва: Астрель-Миф 2002, с. 436.

${ }^{18} \mathrm{~J}$. Seibert, Leksykon sztuki chrześcijańskiej. Tematy, postacie, symbole, tłum. D. Petruk, Kielce: Wydawnictwo Jedność 2007, c. 45.
} 
памяти пытается воссоздать образ любимого города детства. Не мешает в этом даже огромное пространственное расстояние:

Город дальнего детства,

Я слышу сквозь шум морей

Шелест ночного ветра,

В ветвях твоих тополей

(Город, с. 11).

Кузнецова возвращается к истокам русской культуры и гордится своим происхождением. Память о родовом гнезде позволяет заглушить душевное рыдание и стать хотя бы на мгновение счастливой. Реконструируя пространство древней Руси, поэтесса придает ей оттенки волшебности и сказочности. Это идеальный мир любви и полной гармонии, в котором человек поглощен природой и создает вместе с ней единое целое. Память о идеальной стране с прозрачным небом, золотыми полями, садами сирени и дорогами, покрытыми снегом, дает возможность забыть о трудах скитания. Оставленный далеко за морями мир детства, Кузнецова мифологизирует, сравнивая его с великолепной Элладой (Спокойная и грустная отрада, с. 35) и с Эдемом (

Постоянным элементом выстраиваемого Кузнецовой поэтического мира потерянной родины является церковь, образ которой появляется в большинстве анализируемых стихотворений, посвященных России. Церковь, храм, собор - это символы, свойственные литературе русской эмиграции первой волны - не только поэзии, но и прозе. Церковь, как символ православия, объединяла эмигрантов и поддерживала их духовную связь с национальной культурой и традицией. Особенно сильно эти мотивы использовались представителями неореализма - Зайцевым и Шмелевым, с Буниным во главе, но христианская проблематика занимала важное место также и в творчестве учеников последнего. Поэтому не удивляет факт, что обратилась к ним и Кузнецова. Она пользуется этими образами двойственно. В некоторых стихотворениях церковь выступает в роли фона или части восстанавливаемого в памяти пространства «малой» отчизны:

Город широких улиц,

Тенистых улиц-аллей.

Город старинных храмов

И белых монастырей.

(Город, с. 11). 
В сборнике Оливковый сад находятся и стихи, в которых церковь появляется в виде обители, места, в котором можно уединиться, взглянуть вглубь себя и задуматься о смысле жизни (Иконостас, с. 19; Горят изветьы, с. 38; Деревенская месса, с. 61).

Описываемые пейзажи любимой родины во второй части Оливкового сада Кузнецова сравнивает с ландшафтами Франции. Для поэтессы природа - это жизнеутверждающая сила: «Благодарю тебе природа, / За все, чему названия нет» (Мне с каждым часом мир дороже, с. 20). Она прекрасна в каждом месте земли, однако, помимо этой красоты, лирическое «я» не может найти счастья, чувствуя внутреннюю пустоту:

Опять, опять в ветвях тяжелых пальм
Играет ветер утренний, и небо
Нежнее бирюзы над гладью голубой
Пустого моря. [...]
Но что-то мне мешает быть простой,
Доверчивой, беспечной, беспечальной.
(Опять, опять в ветвях тяжельх пальм, с. 32).

Природа чужой страны не приносит утешения, не отвечает на страдания скитальцев. Она приобретает черты враждебного мира. Пейзаж меняется, голубое небо, поля хлебов, блестящие купола уступают серым, высохшим и жестоким поверхностям (В день сияющий, осенний, с. 66), а день - ночи. Земля начинает ассоциироваться не с идиллической обителью, а с «огромным странным садом» (Пролился свет над неподвижным садом, с. 46). Для провансальского ландшафта, по Кузнецовой, характерны «туман», «дым» и «серость» (Над размокиим рыжим тесом, с. 51), облака «пламенеют» (Вокруг сады то гаснут, то светлеют, с. 48) а колокола звонят «печальным звуком» (Печальным звуком колокол звонит, с. 58). Равнодушие природы способствует размышлениям о уходе времени и углублению одиночества (Я возвращалась в сумерки, с. 72). Эта проблема является доминантой стихотворения Все течет, проходит, блекнет, вянет:

Все течет, проходит, блекнет, вянет,

День сменяет день, зима - зиму.

Час пробьет - и дальним светом станет

Все, что мило сердцу моему (с. 40).

Приведенные строки перекликаются со стихотворением Бунина Петух на иерковном кресте: 
[...] Поет о том, что мы живем,

Что мы умрем, что день за днем,

Идут года, текут века,

Вот как река, как облака (с. 18) ${ }^{19}$.

В обоих стихотворениях одинаковое понимание времени, которое предстает как разрушительная сила. Все, что приносит человеку радость, дано ему на мгновение и быстро уходит, оставляя внутри тоску и пустоту. С временем способна бороться только природа, которой свойственна вечность и которая постоянно обновляется и перерождается. Человек в сравнении с необъятной силой природы и времени не стоит ничего. Символом равнодушия естественных сил и их долговечности в художественном мире Кузнецовой являются горы, которые непременно будут гордо стоять и бросать тень даже после смерти людей (Горы, с. 62). Горы - это мотив, отражаемый не только в поэзии, но и в прозе ученицы Бунина. Если в сборнике рассказов Утро их образ выделяется амбивалентностью ${ }^{20}$, то в Оливковом саде преобладает отрицательная семантика. Так, например, в стихотворении Дарданеллы «спины гор» сравниваются c «трупами былых столетий» (c.12), что наводит на мысль проблематику смерти. В других стихах цикла горы вызывают чувство ностальгии и печали. Они показаны ночью в тумане, что способствует раздумьям о смысле жизни и потерянной родине (Сияет даль, с. 39; Колоколов протяжный разговор, с. 42; В сыром пару теряется гора, с. 47). Горы в поэтическом пространстве Кузнецовой часто выступают наряду с образами моря - важного символа всемирной культуры, выделяющегося неоднозначным толкованием. В анализируемом сборнике море выступает в роли аллегории скитальчества, а также усиливает одиночество и сознание безнадежности лирического «я», как это имеет место в стихотворении Колоколов протяжный разговор.

С мотивом ухода времени неразрывно связана танатологическая тематика. Кузнецова реализует ее в пейзажной лирике, которой эмигрантка придает философские ноты. Поэтесса вводит в мир природы такие ванитативные топосы как крест, кладбище, могила, руины. В некоторых стихотворениях Оливкового сада фунеральные мотивы являются второстепенными, составляют ностальгический фон, в других же - проблема смерти доминирует, как, например, в стихотворении Турецкое кладбище:

${ }^{19}$ И. Бунин, Петух на иерковном кресте, [электронный ресурс] http://www.goldpoetry. $\mathrm{ru} / \mathrm{bunin} /$ index.php? $\mathrm{p}=282$ [14.08.2018].

${ }^{20} \mathrm{P}$. Witczak, Tworzenie w cieniu..., c. 64. 
[...] Внизу бубенцы и топот,

Веселая жизнь долин,

А здесь кипарисов шепот

И важный покой вершин.

И кажется: легкой птицей

В столетних ветвях шурша,

Поет над земной гробницей

О вечной жизни душа (с. 13).

В вышеприведенных строках Кузнецова ссылается на символику понятий «вершина» и «низ». В христианской традиции «вершина» ассоциируется со сферой sacrum, т.е. с небесами, божественным миром. «Низ»- это мир человеческий, т.е. profanum, или царство смерти, ведь хороним своих близких в земле ${ }^{21}$. В анализируемом стихотворении «вершина» и «низ» приобретают амбивалентный характер. В первой из приведенных строф противоположная символика - «низ» обозначает жизнь и счастье («веселая жизнь долин»), а «вершина» ассоциируется с потусторонним миром («важный покой вершин»). Неслучайно в лирическом пейзаже Кузнецовой присутствие кипариса, являющегося с давних времен эмблемой смерти. Его часто использовали на кладбищах, так как предполагалось, что это дерево сохраняет тело от разложения ${ }^{22}$. Кузнецова часто возвращается к образу кипариса и в других стихотворениях, опосредованно вводя проблематику смерти (Оставить в мире память о себе, с. 25; По имени назвать тебя не смею, c. 36; В день сияющий осенний, с. 66). В последней строфе Турецкого кладбима «вершина» становится небесным королевством бессмертных душ, а земля сравнивается с гробницей. Таким образом, земная жизнь перестает удовлетворять лирическое «я». Земное существование лишено смысла, смерть является избавлением от мук и путем к вечной беззаботной жизни.

Продолжая наши рассуждения о сборнике Оливковый сад, стоит отметить, что поэтесса в своих стихах пытается доказать, что жизнь на чужбине не имеет смысла, чужая земля все чаще способствует размышлениям о смерти. Даже счастливое прошлое не всегда приносит утешение, ибо расплывается в тумане памяти (В сером пару теряется гора, с. 47). Лирическому «я» не жаль своей жизни, оно желает только одного: уцелеть от забвения:

\footnotetext{
${ }^{21}$ W. Kopaliński, Słownik symboli, Warszawa: Wiedza Powszechna 1991, c. 251-253.

${ }^{22}$ Кипарис, дерево, [в:] Краткая энизилопедия символов, [электронный ресурс] http:// www.symbolarium.ru/index.php/Кипарис,_дерево [1.08.2018].
} 
Оставить в мире память о себе!

Ни имена, ни книги, ни преданья,

Ни скудные друзей воспоминания

Не скажут о земной моей судьбе...

O, если бы на обнаженном мысе

Сияли между смольных кипарисов,

На мраморном, на гробовом гербе

Два слова, посвященные Тебе!

(Оставить в мире память о себе!, с. 25).

Танатос в художественном мире поэзии Кузнецовой часто образует неразрывную пару с Эросом, как и в эмиграционном творчестве Бунина, прежде всего в его любовных рассказах ${ }^{23}$. В книге поэзии Кузнецовой эта проблема затронута в стихотворении Застыла ночь, над облаком ветвей, в котором лирическому «я» снится встреча с любимым:

[...] И снится мне, что мы в саду пустом,

В аллее пальм и в сени их могильной,

И в теплой тьме овеян темный дом

Гелиотропа запахом ванильным.

И мы опять в той сказочной стране,

Где вздохи трав и звезды - все иное,

И ты такой, каким был послан мне

Среди сверканья, золота и зноя (с. 37).

Долгожданная волшебная встреча влюбленных разыгрывается в ванитативной обстановке. «Темный дом», «тьма», «могильная сень» не позволяют добиться полноты счастья и напоминают о кратковременности человеческого бытия. Вечное - это только чувство любви и преданность, которые символизирует гелиотроп. Добавим, что тема любви занимает важное место в сборнике Оливковый сад, однако, она всегда имеет односторонний характер - это несчастная любовь. Возлюбленные не имеют возможности встретиться, прикоснуться друг к другу. Лирическое «я» восстанавливает в памяти образ возлюбленного, которого захватил уход времени.

Подводя итог сказанному, следует подчеркнуть, что хотя Кузнецова оставила небольшое творческое наследие, она внесла весомый вклад

${ }^{23}$ A. Semczuk, O «Ciemnych alejach» Iwana Bunina, [в:] Studia i szkice slawistyczne X..., c. $84-85$. 
в литературную традицию русской эмиграции. Ее самым большим достижением является Грасский дневник, однако писательница удачно пользовалась и другими литературными жанрами. Кузнецова находилась под сильным влиянием Ивана Бунина, которое отразилось и в ее беллетристике, и в поэзии. В стихотворениях эмигрантки воздействие Бунина наиболее выразительно проявилось на тематическом уровне. Писательница, как и ее великий учитель, обратилась к вечным проблемам бытия, таким, как смерть, любовь и уход времени. Важное место в ее лирике занимает также образ утраченной родины. В заключение приведем слова Глеба Струве, который высоко оценивал творчество эмигрантки и также указывал на близость ее стихотворений с лирикой Бунина: «Кузнецова писала хорошие стихи - в ее книге Оливковый сад [...] чувствуется [...] влияние Бунина и акмеистов - неоклассическая закваска: они, скорее, пластичны, чем музыкальны» ${ }^{24}$. Со словами выдающегося исследователя литературы русского зарубежья стоит согласиться.

\section{References}

Brzykcy, Jolanta. “Dziennik z Grasse Galiny Kuzniecowej - autoportret pisarki”. Przegląd Rusycystyczny, r. 38, z. 1 (2016): 27-43.

Brzykcy, Jolanta. Poezja emigracyjna Iwana Bunina (1920-1953). Toruń: Wydawnictwo UMK, 2009. Bunin, Ivan. Petukh na tserkownom kreste. http://www.goldpoetry.ru/bunin/index.php?p=282

Demidova, Olga. Pisatelnitsy russkoi emigratsii: dvazhdy Drugiye. In: Rossica Lubliniensia V: Kobieta i/jako Inny. Mit i figury kobiecości w literaturze i kulturze rosyjskiej XX-XXI wieku (w kontekście europejskim), eds. M. Cymborska-Leboda, A. Gozdek. Lublin: Wydawnictwo UMCS, 2008: 315-330.

Dukhanina, Margarita. «Monastyr muz». $K$ istorii tvorcheskikh $i$ lichnykh vzaimootnoshenii G. N. Kuznetsovoy, I. A. Bunina, L. F. Zurova, V. N. Muromtsevoy-Buninoy, M. A.Stepun. http:// www.vestnik.com/issues/2002/0612/win/dukhanina.htm

Entsiklopediya simvolov, znakov, emblem, eds. V. Andreyeva, V. Kuklev, A. Rovner, E. Yegazarov, Moskva: Astrel-Mif, 2002: 436.

Kopaliński, Władysław. Słownik symboli. Warszawa: Wiedza Powszechna, 1991: 251-253.

Kratkaya entsiklopediya simvolov. http://www.symbolarium.ru/index.php/Кипарис,_дерево

Kuznetsova, Galina. Grasskii dnevnik. Moskva: Astrel, 2008.

Kuznetsova, Galina. Olivkovyy sad. Parizh: Sovremennyye Zapiski, 1937: 1-82.

Mikhailova, Mariya. "Tvorcheskie vzaimootnoshenia Ivana Bunina i Galiny Kuznetsovoi kak konflikt molodosti i starosti”. Slavica Wratislaviensia. No. 163 (2016): 129-137.

Seibert, Jutta. Leksykon sztuki chrześcijańskiej. Tematy, postacie, symbole, transl. D. Petruk, Kielce: Wydawnictwo Jedność, 2007: 45.

Semczuk, Antoni. O “Ciemnych alejach” Iwana Bunina. V: Studia i szkice slawistyczne X: Słowianie wschodni na emigracji. Literatura. Kultura. Język. Opole: Wydawnictwo Uniwersytetu Opolskiego, 2010: 83-88.

${ }^{24}$ Г. Струве, Русская литература в изгнании..., с. 205. 
Sokolov, Aleksandr. Sudby russkoi literaturnoy emigratsii 1920-kh godov. Moskva: Izdatelstvo Moskovskogo universiteta, 1991: 142.

Struve, Gleb. Russkaya literatura v izgnanii. Parizh-Moskva: Russkii Put, 1996: 204-205.

Tsetlin, Mikhail. “Galina Kuznetsova. Olivkovyy sad. Izd. «Sovr. Zapiski». Parizh. 1937». Sovremennyye Zapiski, kn. LXV (1928): 430-431.

Yanovskii, Vasiliy. Polya Yeliseyskie. Moskva: Astrel, 2011: 318.

Witczak, Patryk. “Odchodząca Rosja w powieści “Dawna podróż” Leonida Zurowa”. Acta Neophilologica. Vol. XIX, no. 1 (2017): 227-236.

Witczak, Patryk. “Tworzenie w cieniu mistrza. Kilka uwag o prozie Galiny Kuzniecowej”. Heteroglossia. Studia kulturoznawczo-filologiczne. No. 5, (2015) 55-66. 